\title{
Comparison of Perceptual Reasoning Index of Intelligence between Personalities of Extravert and Ambivert
}

\author{
Nasir Yusoff, Nazirah Hanim Sharipudin, and Muhamad S. B. Yusoff
}

\begin{abstract}
Intelligence is not solely justified from mental capacities, but could be from personality dispositions, characteristics or nature. This study aims to compare the Perceptual Reasoning Index (PRI) of intelligence between extravert and ambivert. Eighty medical undergraduate students from Universiti Sains Malaysia (USM) were participated in this study. The Universiti Sains Malaysia Personality Inventory (USMaP-i) was distributed to the respondents prior to the administration of the Wechsler Adult Intelligence Scale-Forth Edition (WAIS-IV) to measure PRI. No significant difference of PRI between ambivert and extravert was observed. However, significant correlation between estimation and psychometric score of PRI was observed, as well as the significant correlation between self-estimated and psychometric personality. Self-estimated and psychometric measure of personality should be taken into account as profile to form baseline PRI performance. The individual differences and external factors such as age variation and parent's education may confound the study's finding; thus, need to be considered in future research.
\end{abstract}

Index Term-Ambivert, extravert, perceptual reasoning index, personality.

\section{INTRODUCTION}

Personality plays an important role in determining a person's action or emotion when faced with everyday life event whether pleasant or stressful. In [1], personality is said to be made up of three important parts: traits, characteristic adaptations and life stories. One quote even mentioned [2]:

"There is a growing consensus about the validity of human personality traits as important dispositions toward feelings and behaviors" (p.493).

Personality tells many things about a person and provide benefits in many ways; for example, what motivates them, how to cope with stress, social life or depression; which are extremely important for therapist or counselor to get to know their patient better. In other words, methods of treatment can be given if a person is diagnosed with a personality disorder thus improving their lifestyle.

A type of one's personality has been correlated to many other factors such as academics, health problems, employment, social life and even cognitive performance

Manuscript received September 29, 2014; revised November 28, 2014 This research was supported by the Universiti Sains Malaysia Short Term Research Funding (Grant Number: 304/PPSP/61312101).

The authors are with the Department of Neurosciences, School of Medical Sciences, Health Campus, Universiti Sains Malaysia, 16150 Kubang Kerian, Kelantan, Malaysia (e-mail: nasirff@usm.my, nazirah.mpputm@gmail.com,msaiful_bahri@usm.my).
[3]-[5]. Formerly, personality is categorized into three parts which are emotional stability/instability (later known as neuroticism), extraversion/introversion and psychoticism (aggressiveness/antisocial) [6]. Then, [7] proposed a new theory for personalities which are now commonly applied by researchers called the Big Five personalities trait. These are Openness to experience, Conscientiousness, Extraversion, Agreeableness and Neuroticism. These five personalities are discovered when researchers founded five recurrent factors in analyzing personality ratings in eight different samples from their study [8]. Each personality is organized in hierarchical method and differs from one another depending on the underlying traits. However, there was also argument that intelligence should be included under personality and it is closely related to Openness [9]. This shows that intelligence is somehow correlated to personality where it is almost considered as one of the option for personality.

In [10], intelligence is defined as the ability to solve problem including problem of comprehension by thinking abstractly which implies many meanings such as learning, planning, comprehending, imagination, making decisions, perception, and so on. Intelligence is not restricted to only academic's score and the ability to answer problems, but more of how a person is able to make use of their surroundings to their benefits with their intellect which differs for every person. Although there are several competing hierarchical theories regarding intelligence, most theories specify general intelligence $(\mathrm{g})$ as the highest node and broken down into other specific abilities [11], [12]. Previous researches even postulate the validity of using general intelligence rather than narrow cognitive abilities in predicting important life outcomes such as academic and occupational performance [13], [14]. Following the hierarchical level, below the general intelligence indicates as between fluid and crystallized intelligence [15]. Crystallized intelligence is considered as verbal and fluid intelligence is considered nonverbal [16]. With this regard, Psychologist Raymond Cattell in his Cattell-Horn theory of fluid and crystallized intelligence explained how fluid ability of solving problem is less dependent on the experience and knowledge while crystallized knowledge is based on education and experience [17]. Next, from these two types of intelligence, more categories of intelligences have been generated. For example, [18] proposed that intelligence has seven factors - linguistic, logical-mathematical, spatial, musical, bodily kinesthetic, interpersonal, and intrapersonal; which is different from Ackerman's theory [19]. Even though Ackerman's theory proposes the same numbers of factors, however, the classification is different. These are Fluid intelligence, Visual perception, Perceptual speed, Learning 
and memory, Knowledge and achievement, Ideational fluency, and Crystallized intelligence [20].

Basically, each person has their own dominance in what classes or types of intelligence which was influenced by many factors such as genetics, age, schooling background, environment and even personality [21].

Lately, researchers are trying to correlate between each type of personalities to different types of intelligence. Some researchers elucidate personality as predictor to intelligence and how it is degenerated by age [22], [23]. For example, higher Extraversion was associated with worse average cognitive functioning, while persons higher in Conscientiousness showed a slower rate of cognitive decline. The stability of a personality is also affected by the adaptive cognitive performance on reasoning and reaction time [24], [25]. Personality and intelligence have their own influence on one another and both are susceptible to external factors such as age, social life and parental guidance which can affect the stability of either one. However, contradictions between results still exist even after many decades of research has been done in the area.

There had been studies that postulate how important for medical students to have a stable personality as it is correlate to their academic achievement [26], [27]. One of the reasons might be the stressful condition of being in a medical school [28]. If the students do not have a stable personality to cope with the stress, it might induce physical and mental health problems. There is a study stating the presence of emotional disturbances among medical students in Malaysia [29]. This shows the significance of conducting a personality-based research on students as it helps to detect their personality which then can be correlated to their learning styles, academic achievement and performance, mental health [26], [30]-[32]; and also for the future career choices in medicine and career success [33], [34].

Although the link between self-rated personality and psychometric measure of intelligence has been studied for decades, little is still known about the relationship between personality and intelligence. In the case of extraversion, there have already been few reviews made about its relationship to intelligence [35], [36]. According to [37], extraversion is a trait that contains the facets of warmth, gregariousness, assertiveness, activity, excitement seeking, and positive emotion.

The opposite of extraversion is introvert and another term for the intermediate level of both extravert and introvert is ambivert [38]. Ambivert is an individual who possessed both extravert and introvert traits and considered as moderate scorers on extraversion scale test [39]. In [40], a person whose personality contains opposites (extravert/introvert) are considered as creative. Besides that, other trait has been found in [40] which are considered creative or in the same context as ambiverts are smart/naive, disciplined/playful, humble/proud, and rebellious/conservative. Contradict to [41], [42], one study proved that extravert had better performance in non-verbal task while introvert is better in verbal-related tasks outdoing both ambiverts and extraverts [43]. Another study showed extraverts performing slightly better in timed task contrary to introverts [44]. However, both findings failed to be reenacted by other researchers, hence making it difficult to support the results for both studies [45], [46]. Robinson compensate for this complications by suggesting correlation between electroencephalogram (EEG) characteristics with intelligence score, resulting in ambiverts performing better on the tests than either extravert or introvert [38]. Then, [47] proposed that introverts were advantageous in task related to superior associative learning ability (Verbal task) and Extravert excel in task comprising in acquisition of automatic motor sequences (performance task). Thus, for deduction, extraverts are suited to faster speed in performance and lack of persistence during tests but the findings are still ambiguous [48]. Moreover, several studies also showed changes from positive to negative correlations between extraversion and a variety of intelligence measures [49], [50]. Related to this, [51] commented the factors for contradictions in research's findings were due to year of publication, difference between the methods used to measure extraversion and intelligence and also the age of subjects.

This research aims to investigate the level of intelligence in order to establish a link between type of personality and intelligence. This study focuses specifically on comparing perceptual reasoning index of intelligence between different types of personalities - extravert and ambivert. The Perceptual Reasoning Index is chosen due to its psychometric properties in measuring most of the characteristics for fluid intelligence. It infers that fluid intelligence as more subtle and declining due to genetic or environmental ageing factors [52]. This opposes to crystalized intelligence which maintains the ability to learn using pre-existing knowledge throughout the aged [53]. By targeting on medical undergraduates who have considerable marked level of education and IQ, this confounding factor should be minimized therefore enable more accurate assessment on the influence of parameters of the interest on perceptual reasoning performance task. Thus, throughout this study, we postulate null hypotheses as follows: (1) There is no significant difference of Perceptual Reasoning Index (PRI) between extravert and ambivert; (2) There is no correlation between self-estimated and psychometric personality; (3) There is no correlation between psychometric and estimation of PRI.

\section{Methodology}

\section{A. Subject}

Data was collected and analyzed from undergraduate medical students from School of Medical Sciences, Universiti Sains Malaysia (USM). This data is part of the research that is still in progress, sponsored by Universiti Sains Malaysia short term research grant. Respondents were selected based on inclusion criteria, these were 1) Undergraduate medical students who were pursuing medical degree at PPSP, Health Campus, USM; 2) Year one until year five with aged ranged from 18 to 24 years old, 3) Regardless of gender and ethnicity (Malay, Chinese, Indian, others). However, those who have significant chronic psychiatric condition such as depression or taking any psychiatric medication were excluded from this study.

\section{B. Measures}

\section{1) Extraversion}

The Extraversion Subscale of the Universiti Sains Malaysia Personality Inventory (USMaP-i) was used to 
measure extravert trait of personality [54]. The full version of the scale consists 66 items with 0 to 4 rating scales (1=Moderately Inaccurate, 2=Neither Inaccurate nor Accurate, $3=$ Moderately accurate). This full version of $U S M$ Personality Inventory (USMaP-i) covers five main areas of personality-neuroticism, extraversion, openness to experience, agreeableness, and conscientiousness. It indicates good psychometric properties and valid to be used for personality measure [55]-[56]. For this study, twelve items were used to measure extraversion, out of 66 items. These items are 2, 7, 10, 12, 18, 25, 27, 32, 36, 55, 57 and 62 . The following cut-off score was used to classsify the different trait of personality [54]. Extraversion was indicated by scores from 33 and above. Meanwhile, ambiversion was presented by scores from 17-32. Scores below 17 indicated introversion. However, those with introversion trait were excluded from analysis as the focus of the study is to examine the differences of the Perceptual Reasoning Index between extraversion and ambiversion.

\section{2) Perceptual reasoning index}

The Perceptual Reasoning Index from the Wechsler Adult Intelligence Scale-Fourth edition (WAIS-IV) [57] was utilized to measure perceptual reasoning. The WAIS-IV is the fourth edition from the series of the well-known WAIS test (introduced by David Wechsler in 1955) to measure the intelligence through administration of numerous related cognitive task [58]. The subtest of Perceptual Reasoning Index (PRI) consists of the series of tests such as Block Design (BD), Matrix Reasoning (MR) and Visual Puzzles (VP) with the supplementary test such as Figure Weights (FW) and Picture Completion (PCm). The BD measures non-verbal reasoning; visual perception and organization; and visual-motor coordination. Meanwhile, the MR measures fluid intelligence, visuospatial ability, simultaneous processing, and perceptual organization. Perceptual reasoning, visuospatial ability, analysis and synthesis, and simultaneous processing are the specific areas covered by the VP. For the FW, it measures fluid reasoning, which is different from the PCm which focus on visual perception, perceptual organization, and attention to visual detail. Combination of these three core subtest $(\mathrm{BD}+\mathrm{MR}+\mathrm{VP})$ will provide the level of PRI for tested subjects.

Each subtest has different types of intelligence measure, which could be accumulated to perform the level of perceptual reasoning index (PRI) of intelligence. The timing for timed-subtests is very important and need to be precised as extra time will results in zero marks. The scores for both BD and VP depend on the time allocated for each questions while MR depends on the correct answer. The raw score accumulated from these three core subtests made up a total composite score of PRI.

\section{Procedure}

Prior to the participation in the study, respondents were explained thoroughly of the objective of the study and were asked to give their signature for the consent form upon the agreement to participate in the study. Participants could forfeit at any time on their own choice as the participation is voluntary. Recruitment of the respondents was implemented by using purposive sampling, based on the inclusion and exclusion criteria of the study (see the section of subject). Cognitive test for perceptual reasoning was held at the Clinical Neuroscience Laboratory, Universiti Sains Malaysia. Prior to the cognitive test, personality screening was implemented by using standardized personality questionnaires to identify the personality of the respondents. Only respondents with extraversion and ambiversion trait were included in this study, meanwhile those with introversion trait were excluded. The classification procedure (based on cut off score) has been described in detail in the previous section. The instruction and items of the questionnaires could be understood easily and respondents took about 10-15 minutes to complete each questionnaire. Meanwhile, for the perceptual reasoning test, the test was facilitated by the researcher and clinical psychologist. Respondents were first explained on how the task will be carried out before running the test. Some subtests were timed, thus, respondents needed to perform the task within the time limit with guidance from the researcher. In this study, only three main tests were implemented. These were the Block Design, Matrix Reasoning and Visual Puzzles, to perform the level of perceptual reasoning intelligence of the tested respondents. Ethical approval has been obtained from the Human Research Ethics Committee of Universiti Sains Malaysia.

\section{RESUlTS}

\section{A. Socio-Demographic Data of the Respondents}

Socio-demographic data of the respondents according to gender, ethnic and previous educational background is presented in Table I. The subjects consisted of 82 medical undergraduate students who fulfilled both the inclusion and exclusion criteria for the sample characteristics. Majority of the subjects were female, Malay and had previous educational background from matriculation. The personality types were equally obtained between extraverts and ambiverts. The results were analyzed according to the objectives of the study respectively.

\section{B. Difference of Perceptual Reasoning Index between Extravert and Ambivert}

The data obtained fulfilled the assumptions for Independent t-test and the $p$-value calculated was greater than 0.05 ( $p$-value $=0.329)$; thus accepting the null hypothesis which stated that there is no significant difference of Perceptual Reasoning Index (PRI) between ambivert and extravert (see Table I-Table II).

\section{Correlation between Estimation and Psychometric Score of Perceptual Reasoning Index}

Perason correlation was used to determine the correlation between psychometric score and estimation score for perceptual reasoning of intelligence. The strength of correlation, $r$ calculated is positive and fair which is 0.423 ; meanwhile the $p$ value is less than 0.01 , so the null hypothesis which stated that there is no correlation between psychometric and estimation score for Perceptual Reasoning Index (PRI), is rejected. Thus, there is statistically significant positive and fair strength of correlation between estimation 
score and psychometric score for perceptual reasoning of intelligence (see Table III).

TABLE I: SOCIODEMOGRAPHIC DATA OF THE RESPONDENTS $(N=82)$

\begin{tabular}{ll}
\hline Variables & $N(\%)$ \\
\hline Gender: & \\
Male & $25(30.5)$ \\
Female & $57(69.5)$ \\
& \\
Ethnic: & \\
Malay & $51(62.2)$ \\
Chinese & $16(19.5)$ \\
Indian & $13(15.9)$ \\
Others & $2(2.4)$
\end{tabular}

Previous educational background:

$\begin{array}{ll}\text { Matriculation } & 62(75.6) \\ \text { Foundation } & 7(8.5) \\ \text { STPM } & 8(9.8) \\ \text { Diploma/A-levels } & 5(6.1)\end{array}$

Note: Mean age, 21.35 \pm SD 1.06 years old.

STPM: Certificate of Higher Education, Malaysia.

TABLE II: THE DIFFERENCE OF PERCEPTUAL REASONING INDEX (PRI) BETWEEN EXTRAVERT AND AMBIVERT

\begin{tabular}{cccc}
\multicolumn{4}{c}{ BETWEEN EXTRAVERT AND AMBIVERT } \\
\hline Extravert & $101.37( \pm 12.97)$ & $-0.983(80)$ & $0.329^{*}$ \\
Ambivert & $104.12( \pm 12.42)$ & & \\
\hline
\end{tabular}

*Not Significant

TABLE III: PEARSON CORRELATION BETWEEN PSYCHOMETRIC AND ESTIMATION SCORE OF PERCEPTUAL REASONING INDEX (PRI)

\begin{tabular}{lcc}
\hline \multicolumn{1}{c}{ Variable } & PRI Estimation Score & $p$-value \\
\hline PRI Psychometric Score & 0.423 & $0.001^{*}$ \\
\hline$* p<0.01$ & & \\
\end{tabular}

\section{Correlation between Self-Estimated and Psychometric} Personality

TABLE IV: CORRELATION BETWEEN PSYCHOMETRIC AND SELF-ESTIMATED PERSONALITY

\begin{tabular}{lcc}
\multicolumn{3}{c}{ SELF-ESTIMATED PERSONALITY } \\
\hline Ambivert $^{\mathrm{a}}$ & Extravert $^{\mathrm{a}}$ \\
\hline Extravert $^{\mathrm{b}}$ & $16(19.5)$ & $2(2.4)$ \\
Ambivert $^{\mathrm{b}}$ & $25(30.5)$ & $39(47.6)$
\end{tabular}

Note: $\mathrm{a}=$ Psychometric; $\mathrm{b}=$ Estimation; $X^{2}$-stat $(\mathrm{df})=13.95(1) ; p<0.01$

Cross tabulation was used to analyze the correlation between psychometric and self-estimated personality. Data fulfilled the assumptions for chi-squared test. There is significant correlation between self-estimated and psychometric personality with $p<0.01$ (Table IV). Thus, the null hypothesis which stated that there is no correlation between self-estimated and psychometric personality, is rejected.

\section{DISCUSSION}

\section{A. Comparison of Perceptual Reasoning Index between Extravert and Ambivert}

Different types of personalities (extravert and ambivert) did not affect the measure of Perceptual Reasoning Index
(PRI). The present finding contradicted to most studies which stated that the certain types of personality have its own dominance in intelligence [59], [60]. However, the current study differed in terms of having smaller scale in comparing between general intelligence with the big five personality. In terms of the Wechsler Adult Intelligence Scale-Fourth edition (WAIS-IV) intelligence test, the PRI test covers only a quarter of the general intelligence. Three other tests from the WAIS-IV are required for a complete general intelligence measure.

There are three subtests which made up the PRI test, Block Design (BD), Matrix Reasoning (MR) and Visual Puzzle (VP). Two subtests, BD and VP, are both time-limited task and MR are untimed task. From previous study, it being mentioned that intelligence scores of an extravert were affected by their behavior depending on the characteristics of the test [61] and they were shown to have an advantage and better in time-related task compared to introvert [62], [63]. Furthermore, in arousal theory [38], it said that extraverts might prefer arousing test-taking situation and ambiverts prefer a normal situation. However, previous study failed to prove the theory due to sample unsuitable for the test and not reasonable amount of arousal from the tests used (they use ability test only) [39].

For the current study, applying all the theories with the characteristics of PRI subtest, both BD and VP were in favor towards extraverts and MR would be optimum for ambiverts. The BD tests are intermediate arousal level which favors the ambiverts while the timed-limited features gave advantage to the extraverts. Then, the MR has unlimited time which is suitable with ambiverts while the VP must be completed under a very short time of 30 seconds, giving the upper-hand to extravert who was better in time-related task. Therefore, the performance or test score of both personality types were possibly equally distributed between the tests, resulting in extraverts and ambiverts scoring almost the same on PRI test. Almost similar situations were discovered in [41], [42]. In these studies, intelligence measure detected the differences in the subtests score only, but indicated similarity in full scale scores for both extravert and introvert.

Majority of ambivert and extravert were categorized as average scorer on the PRI of intelligence test and the rest were vaguely varied between the PRI categories of intelligence. Besides, observations during the test showed extraverts were likely more active and participative in answering while ambiverts were sometimes reserved but also get competitive as the question becomes complex. However, ambiverts were indecisive at times while extraverts were confident when answering the subtests. As stated by [64], extraverts would rather answer quickly rather than obtain accuracy when taking ability test.

In addition, there were no variations in the intelligence test given. If other intelligence test were applied, the cognitive performance for extravert and ambivert might differ depending on the type of test. As example, if given Verbal Comprehension of intelligence test (verbal task), ambivert might score higher compared to extravert. Previous studies had mentioned introverts were better in verbal-related task compared to extravert [41], [64]. Therefore, having half of introversion traits, ambiverts might be suited for verbal type 
task and scored higher for the task than Extravert. Thus, the general intelligence could be obtained and the probability of discovering different level of intelligence between extravert and ambivert might be higher.

On top of that, the types of intelligence which were studied previously in correlation with personality for extroversion traits were mostly for extraverts and introverts [65], [66]. Both types of personality were clearly different in terms of positive and negative degree. Hence, both personality types have a clear dominance in their own type of intelligence or performance. In the case of ambiverts, they have the personality traits of both extraverts and introverts, or in other words - creative (a creative person was reported to have both traits of extraversion and introversion), resulting in the risk of being unstable as which traits will be more dominant [40], [42], [67]. Thus, by having both types of traits, it is possible that ambiverts also occupy both type of intellect found in extraverts and introverts. Previous study contribute to this statement by providing results where ambivert usually have small and least amount of variance across the tests score, never reaching extremely high or low achievement compared to extravert and introvert [61], [68], [69].

Therefore, given the same type of test for PRI, both extravert and ambivert were able to score almost the same average score. The difference in traits between extravert and ambivert were not very evident as compared to introvert. As stated from few studies; the neural or biochemical systems are believed to differ if the person had high or low assessment on a specific trait [70], [71]. Moreover, there was also a study that mentioned different degree of extraversion effect the executive function of the brain [72]. Since ambiverts are intermediary of extroversion trait, the performance, abilities or the cognitive state of extraverts and ambivert might not vary so much, supporting the result obtained. Thus, in summary, the contrast between ambivert and extravert types of personality is not as strong as what previous study had done between extravert and introvert, as ambiverts still had half of extravert' traits. In addition, the current study focused on one type of intelligence which is PRI. Hence, the result of no significant difference of PRI between extravert and ambient was obtained.

\section{B. Correlation between Estimation and Psychometric Score of Perceptual Reasoning Index}

There was a significant positive and fair strength of correlation between estimation score and psychometric score for the perceptual reasoning of intelligence. In other words, the subjects were able to predict or estimate correctly their range of scores obtained from the intelligence test. This also portrays their confidence in their own intelligence and how far they know themselves. However, it showed that 35 out of 82 subjects, which were the majority, estimate themselves to score average as compared to other type of intelligence score. Overall, out of 82 subjects, 42 subjects were able to obtain the same score as predicted. This was followed by 23 subjects who were humbled and estimated themselves to score lower than their real score. Other than that, there were subjects who were really confident and satisfied with their answer for the test which lead them to estimate their score higher than their psychometric score.

By being able to estimate their score, it actually helps in developing a mindset or goals in their mind to achieve that score. So, it actually contributes to motivate the subjects to obtain what they wanted. In theory that is little bit similar to the theory of self-efficacy [73] stated that one's belief in one's ability to succeed in specific situations. [73] described those with high self-efficacy usually will put more effort into a task and approach the task more positively. Therefore, the self-estimation factor did present effect on the psychometric score obtained whether for personality and intelligence.

\section{Correlation between Self-Estimated and Psychometric Personality}

There is significant correlation between self-estimated personality type and psychometric personality type. An elaboration of this finding, similar to intelligence, is how the subjects interpret their personality is related to their actual personality. In simpler terms, the way the subjects see themselves, reflecting their real personality. Majority of the subjects who were able to estimate their personalities correctly were the ambiverts while only 16 extravert subjects were able to correctly predict their personality. Most of the extraverts thought of having ambiversion as their personality and two subjects whom are ambivert thought the opposite. The reason ambiversion were mostly selected by the students was because they explained themselves being reserved and quiet, but sometimes enjoy talking to others. These are certainly parts of traits for ambiversion [74], so they were able to estimate their personalities fairly accurate as they understand the description. However, for the extraverts whose opinions differ from their actual traits might have misunderstood the main traits for extraversion were focused merely on being talkative. By being energetic, active, friendly and does not mind always being surrounded by people were also traits of an extravert [74]. Previous study [75] also supported this result by revealing that extraverts were not much aware of their extraversion compared to introverts. Therefore, having somehow misinterpreted the definition, they were not able to estimate their personality correctly. This theory was supported from a study that mentioned "the subject must be familiar with the psychological concept, be clear about the situations or phenomena to which it applied" (p. 26), to be able to predict the score correctly [76].

Other interpretation of these data might be the subjects predicted the personality that they wanted to achieve, thus resulting in them having said personality. In addition, external factors such as the spur of the moment, the situation and their emotion during answering might had effects on their score and estimation properties. The score obtained for the personality test also had a one point difference between extravert and ambivert, thus the estimation were not entirely mistaken. By being able to correctly predict their personality, it shows the subjects has high understanding of their traits and behavior, which provide to be very advantageous to oneself. It is significant for a person to at least understand their own personality so that they can control their behavior and weakness, thus choosing the appropriate career, task or profession which is suitable where they are able to perform their full potential.

Future research should be conscious with external factors such as age, environment, genetics, education and so on, 
which could affect personality and intelligence. All these factors should also be investigated as they could also be a mediator or predictor to find the association between personality and intelligence. Moreover, a vast mixture of subjects' background should be considered because the type of subject could also contribute to the variation of results.

\section{ACKNOWLEDGMENT}

Author thanks Universiti Sains Malaysia, Kubang Kerian, Kelantan, Malaysia for the financial support and research facilities.

\section{REFERENCES}

[1] D. P. McAdams and J. L. Pals, "A new big five: Fundamental principles for an integrative science of personality," American Psychologist, vol. 61, no. 3, pp. 204, 2006.

[2] G. Matthews, I. J. Deary, and M. C. Whiteman, Personality Traits, Cambridge University Press, 2003.

[3] M. C. O'Connor and S. V. Paunonen, "Big Five personality predictors of post-secondary academic performance," Personality and Individual Differences, vol. 43, no. 5, pp. 971-990, 2007.

[4] A. D. Fabio and D. H. Saklofske, "Comparing ability and self-report trait emotional intelligence, fluid intelligence, and personality traits in career decision," Personality and Individual Differences, vol. 64, pp. $174-178,2014$

[5] C. S. Dunkel and D. V. D. Linden, "Evidence for the general factor of personality as social-effectiveness," Personality and Individual Differences, vol. 64, pp. 147-151, 2014.

[6] H. J. Eysenck, "Dimensions of personality: 16, 5 or 3? - Criteria for a taxonomic paradigm," Personality and Individual Differences, vol. 12, no. 8, pp. 773-790, 1991

[7] P. T. Costa and R. R. M. Crae, Revised NEO Personality Inventory (NEO PI-R) and NEO Five-Factor Inventory (NEO FFI): Professional Manual, Psychological Assessment Resources, 1992.

[8] E. C. Tupes and R. E. Christal, "Recurrent personality factors based on trait ratings," Journal of Personality, vol. 60, no. 2, pp. 225-251, 1992

[9] R. B. Cattell, Personality: A Systematic Theoretical and Factual Study, New York, NY: McGraw-Hill, 1950.

[10] L. S. Gottfredson, "Mainstream science on intelligence: An editorial with 52 signatories, history, and bibliograph," Intelligence, vol. 24, no. 1, pp. 13-23, 1997.

[11] W. Johnson and T. J. Bouchard, "The structure of human intelligence: It is verbal, perceptual, and image rotation (VPR), not fluid and crystallized, " Intelligence, vol. 33, no. 4, pp. 393-416, 2005.

[12] W. Johnson and T. J. Bouchard, "Constructive replication of the visual-perceptual-image rotation model in Thurstone's (1941) battery of 60 tests of mental ability," Intelligence, vol. 33, no. 4, pp. 417-430, 2005.

[13] I. J. Deary, "Introduction to the special issue on cognitive epidemiology," Intelligence, vol. 37, no. 6, pp. 517-519, 2009.

[14] L. Gottfredson and D. H. Saklofske, "Intelligence: Foundations and issues in assessment," Canadian Psychology, vol. 50, no. 3, pp. 183, 2009.

[15] J. L. Horn and R. B. Cattell, "Refinement and test of the theory of fluid and cryst allized general intelligences," Journal of Educational Psychology, vol. 57, pp. $253-270,1966$.

[16] B. E. Postlethwaite, "Fluid ability, crystallized ability, and performance across multiple domains: A meta-analysis," Ph.D dissertation,University of Iowa, 2011.

[17] R. B. Cattell, Abilities: Their Structure, Growth, and Action, New York: Houghton Mifflin. ISBN 0-395-04275-5, 1971.

[18] H. Gardner, Frames of Mind: The Theory of Multiple Intelligences, Basic Books, 1983

[19] P. L. Ackerman, "Personality, self-concept, interests, and intelligence: Which construct doesn't fit?" Journal of Personality, vol. 65, no. 2, pp.171-204, 1997.

[20] P. L. Ackerman and E. D. Heggestad, "Intelligence, personality, and interests: Evidence for overlapping traits," Psychological Bulletin, vol. 121, no. 2, pp. 219, 1997

[21] W. Weiten, Concept Charts for Study and Review: for Psychology, Themes and Variations, 6th ed, Thomson:Wadsworth, 2004.

[22] M. Crowe, "Personality and risk of cognitive impairment 25 years later," Psychology Aging, vol. 21, no. 3, pp. 573-80, 2006.
[23] B. Chapman, "Personality predicts cognitive function over 7 years in older persons," American Journal of Geriatric Psychiatry, vol. 20, no. 7, pp. 612-21, 2012.

[24] E. K. Graham and M. E. Lachman, "Personality stability is associated with better cognitive performance in adulthood: are the stable more able?," J Gerontol B Psychol Sci Soc Sci, vol. 67, no. 5, pp. 545-54, 2012.

[25] A. Soubelet and T. A. Salthouse, "Personality-cognition relations across adulthood," Developmental Psychology, vol. 47, no. 2, pp. 303-10, 2011.

[26] F. Lievens, "Medical students' personality characteristics and academic performance: A five-factor model perspective," Medical Education, vol. 36, no. 11, pp. 1050-1056, 2002.

[27] C. Hoschl and J. Kozeny, "Predicting academic performance of medical students: The first three years," American Journal of Psychiatry, vol. 154, no. 6, p.87, 1997.

[28] M. S. B. Yusoff, A. F. A. Rahim, and M. J. Yaacob, "Prevalence and sources of stress among Universiti Sains Malaysia medical students," The Malaysian Journal of Medical Sciences, vol. 17, no. 1, p.30, 2010

[29] M. S. Sherina, L. Rampal, and N. Kaneson, "Psychological stress among undergraduate medical students," Medical Journal of Malaysia, vol. 59, pp. 207-11, 2004.

[30] A. Soubelet and T. A. Salthouse, "Personality-cognition relations across adulthood," Development Psychology, vol. 47, no. 2, pp. 303-10, 2011.

[31] A. E. Poropat, "A meta-analysis of the five-factor model of personality and academic performance," Psychological Bulletin, vol. 135, no. 2, p. $322,2009$.

[32] S. Trapmann, "Meta-analysis of the relationship between the Big Five and academic success at university," Journal of Psychology, vol. 215, no. 2, pp.132-151, 2007.

[33] S. E. Seibert and M. L. Kraimer, "The five-factor model of personality and career success," Journal of Vocational Behavior, vol. 58, no. 1, p. $1-21,2001$

[34] I. McManus, "Career preference and personality differences in medical school applicants," Psychology, Health \& Medicine, vol. 1, no. 3, pp. 235-248, 1996.

[35] D. H. Saklofske and M. Zeidner, International Handbook of Personality and Intelligence, Springer, 1995.

[36] M. Zeidner and G. Matthews, "Intelligence and personality," Handbook of Intelligence, New York: Cambridge University Press, 2000.

[37] P. T. Costa and R. R. M. Crae, "Four ways five factors are basic," Personality and Individual Differences, vol. 13, no. 6, pp. 653-665, 1992.

[38] D. L. Robinson, "The neurophysiological bases of high IQ," International Journal of Neuroscience, vol. 46, no. 3-4, pp. 209-234, 1989.

[39] M. J. Roberts, "The relationship between extraversion and ability," Personality and Individual Differences, vol. 32, no. 3, pp. 517-522, 2002.

[40] M. Csikszentmihalyi, Flow and the Psychology of Discovery and Invention, New York: HarperPerennial, 1997.

[41] D. L. Robinson, "How personality relates to intelligence test performance: Implications for a theory of intelligence, ageing research and personality assessment," Personality and Individual Differences, vol. 6, no. 2, pp. 203-216, 1985.

[42] D. L. Robinson, "The wechsler adult intelligence scale and personality assessment: Towards a biologically based theory of intelligence and cognition," Personality and Individual Differences, vol. 7, no. 2, pp.153-159, 1986.

[43] M. Luciano, M. J. Wright, and T. C. Bates, "Response to robinson," Personality and Individual Differences," vol. 44, no. 3, pp. 777-779, 2008.

[44] D. Rawlings and D. Carnie, "The interaction of EPQ extraversion with WAIS subtest performance under timed and untimed conditions," Personality and Individual Differences, vol. 10, no. 4, pp. 453-458, 1989.

[45] D. Rawlings and M. Skok, "Extraversion, venturesomeness and intelligence in children," Personality and Individual Differences, vol 15, no. 4, pp. 389-396, 1993.

[46] D. Saklofske and D. Kostura, "Extraversion-introversion and intelligence," Personality and Individual Differences, vol. 11, no. 6, pp. $547-551,1990$

[47] M. Zeidner, "Personality trait correlates of intelligence," International Handbook of Personality and Intelligence, New York: Plenum Press, 1995, pp. 299-319. 
[48] T. C. Premuzic and A. Furnham, Personality and Intellectual Competence, Mahwah: Lawrence Erlbaum Associates, 2005.

[49] A. L. Ackerman and E. D. Heggestad, "Intelligence, personality, and interests: evidence for overlapping traits," Psychological Bulletin, vol. 121, no. 2, p. 219, 1997.

[50] P. L. Ackerman, "Determinants of individual differences and gender differences in knowledge," Journal of Educational Psychology, vol. 93 no. 4, p. 797, 2001.

[51] M. B. Wolf and P. L. Ackerman, "Extraversion and intelligence: A meta-analytic investigation," Personality and Individual Differences, vol. 39, no. 3, pp. 531-542, 2005

[52] F. Craik and T. Salthouse, Handbook of Aging and Cognition, New York, USA: Psychology Press, 3rd edition, 2008.

[53] L. Backman, B. J. Small, A Wahlin, and M Larsson, Cognitive Functioning in very Old Age, Lawrence Erlbaum Associates Publishers, 2000.

[54] M. Yusoff, A. Rahim, and A. R. Esa. (2010). The USM Personality Inventory (USMaP-i) Manual. [Online]. Available: http://www. medic usm.my/dme/images/stories/staff/KKMED/2010/manual\% 20usmap-i. pdf.

[55] M. S. B. Yusoff, "The validity and reliability of the USM personality inventory (USMaP-i): Its use to identify personality of future medical students," International Medical Journal, vol. 18, no. 4, pp. 283-287, 2011.

[56] M. S. B. Yusoff, "Stability of the USMaP-i in measuring the Big Five personality traits," International Medical Journal, vol. 20, no. 1, pp. $1-3,2013$.

[57] D. Wechsler, Wechsler Adult Intelligence Scale-Fourth Edition (WAIS-IV), 2008

[58] G. L. Canivez and M. W. Watkins, "Investigation of the factor structure of the Wechsler Adult Intelligence Scale-Fourth Edition (WAIS-IV) Exploratory and higher order factor analyses," Psychological Assessment, vol. 22, no. 4, p. 827, 2010.

[59] R. Mottus, J. Allik, K. Konstabel, E. M. Kangro, and H. Pullmann, "Beliefs about the relationships between personality and intelligence," Personality and Individual Differences, vol. 45, no. 6, pp. 457-462, 2008.

[60] J. Moutafi, A. Furnham, and L. Paltiel, "Can personality factors predict intelligence?," Personality and Individual Differences, vol. 38, no. 5, pp.1021-1033, 2005.

[61] T. C. Bates and A. Rock, "Personality and information processing speed: Independent influences on intelligent performance," Intelligence, vol. 32, no. 1, pp. 33-46, 2004

[62] A. Furnham, J. Moutafi, and T. C. Premuzic, "Personality and intelligence: Gender, the Big Five, self-estimated and psychometric intelligence," International Journal of Selection and Assessment, vol. 13, no. 1, pp. 11-24, 2005.

[63] D. Rawlings and D. Carnie, "The interaction of EPQ extraversion with WAIS subtest performance under timed and untimed conditions," Personality and Individual Differences, vol. 10, no. 4, pp. 453-458, 1989.

[64] D. Saklofske and M. Zeidner, International Handbook of Personality and Intelligence, New York: Plenum, 1995.

[65] C. G. DeYoung, "Intelligence and personality," The Cambridge Handbod of Intelligence, Cambridge University Press, 2011, pp. 711-737.

[66] D. H. Saklofske and M. Zeidner, International Handbook of Personality and Intelligence, Springer, 1995.

[67] E. V. Hoff, I. M. Carlsson, and G. J. W. Smith, "Personality," Handbook of Organizational Creativity, Academic Press, 2012, pp. 241-270.

[68] V. I. Investment, Personality Associations, The Wiley-Blackwell handbook of individual differences, vol. 2, p. 217, 2011.

[69] W. Revelle, P. Amaral, and S. Turriff, "Introversion/extroversion, time stress, and caffeine: Effect on verbal performance," Science, vol. 192, no. 4235 , pp. $149-150,1976$
[70] F. D. Fruyt, L. V. D. Wiele, and C. V. Heeringen, "Cloninger's psychobiological model of temperament and character and the five-factor model of personality," Personality and Individual Differences, vol. 29, no. 3, pp. 441-452, 2000.

[71] H. J. Eysenck, Handbook of Personality. Theory and Research, New York, NY: Guilford Press, 1990.

[72] A. M. Campbell, D. B. Davalos, D. P. McCabe and L. J. Troup, "Executive functions and extraversion," Personality and Individual Differences, vol. 51, no. 6, pp.720-725, 2011.

[73] A. Bandura, Self-Efficacy: The Exercise of Control, New York, NY: Freeman, 1997.

[74] M. S. B. Yusoff, A. F. A. Rahim, and A. R. Esa, The USM Personality Inventory (USMaP-i) Manual, Malaysia: KKMED Publications, 2010

[75] F. Vingoe, "Validity of the Eysenck extraversion scale: replication and extension," Psychological Reports, vol. 22, no. 3, pp. 706-708, 1968.

[76] L. R. Goldberg, "The development of markers for the Big-Five factor structure," Psychological Assessment, vol. 4, no. 1, p. 26, 1992.

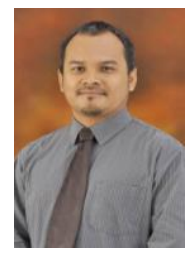

Mohd Nasir Che Mohd Yusoff was born in Selangor, Malaysia in 1975. He received his bachelor of degree science, specialization in social health from Universiti Putra Malaysia, Serdang, Selangor, Malaysia in 1998. he received his master of science from the Universiti Sains Malaysia, Kubang Kerian, Kelantan, Malaysia in 2002, with specialization in medical science. Dr Mohd Nasir Che Mohd Yusoff was awarded the degree of doctor of philosophy with specialization in health psychology in 2009 from University of Malaya in Kuala Lumpur, Malaysia

$\mathrm{He}$ is currently working as senior lecturer at the Department of Neurosciences, School of Medical Sciences, Health Campus, Universiti Sains Malaysia, 16150, Kubang Kerian, Kelantan.

Currently Dr Yusoff is actively participating in neuroscience club association for Kelantan Malaysia Chapter. This association is headed by the United State of America Neuroscience Club. Under this association, many activities have been implemented at society level by the financial support provided by the club.

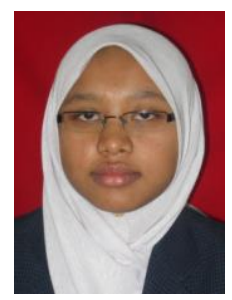

Nazirah Hanim Sharipudin was born in Kota Bharu, Malaysia in 1990. She received her bachelor of degree biomedical engineering from the Universiti Teknologi Malaysia, Skudai, Johor in 2012.

She is currently studying master of neuroscience at the Department of Neurosciences, School of Medical Sciences, Health Campus, Universiti Sains Malaysia, 16150, Kubang Kerian, Kelantan.

Currently Miss Sharipudin is actively participating in neuroscience club association for Kelantan Malaysia Chapter. This association is headed by the United State of America Neuroscience Club. Under this association, many activities have been implemented at society level by the financial support provided by the club.

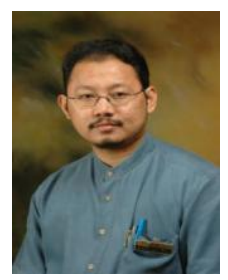

Muhamad Saiful Bahri Yusoff was born in Kota Bharu Kelantan Malaysia in 1981. He obtained medical doctor degree in 2005 from Universiti Sains Malaysia. In 2009, he was awarded with master in medical education from Universiti Sains Malaysia Few years after that, he obtained doctor of philosophy in medical education from the same university. He is currently working as senior lecturer at Department of Medical Education, School of Medical Sciences, Health Campus, Universiti Sains Malaysia, Kubang Kerian, Kelantan. Currently Dr Yusoff is actively participating in editorial board of Education in Medicine Journal as the Editor in Chief. 